\title{
Caracterização dos Efeitos da Imunoterapia com OncoTherad no Câncer de Bexiga Não- Músculo Invasivo: Análise da Regressão Tumoral e Sobrevida Pós-Tratamento.
}

\author{
Melissa Sena da Silva*, Queila Cristina Dias, Nelson Durán, Wagner José Fávaro.
}

\section{Resumo}

O câncer de bexiga urinária não-músculo invasivo (CBNMI) representa $70 \%$ dos carcinomas uroteliais e embora tenham uma sobrevivência prolongada, os pacientes que sofrem desta doença apresentam altas taxas de recorrência tumoral. O tratamento primário do CBNMI baseia-se no tratamento cirúrgico através da ressecção transuretral, seguido da imunoterapia com Bacillus Calmette-Guerin (BCG), no entanto os efeitos colaterais estão presentes em mais de $90 \%$ dos pacientes tratados com BCG. Diante deste cenário, nosso grupo de pesquisa desenvolveu um composto sintético com propriedades antitumorais e imunológicas, denominado OncoTherad. O OncoTherad teve sua segurança e eficácia comprovada em testes com animais e vem sendo administrado em pacientes humanos com câncer de bexiga recidivante, quando todas as alternativas de tratamento foram esgotadas, com excelentes resultados e mínimos efeitos colaterais. Assim, os objetivos deste estudo foram caracterizar os efeitos histopatológicos da imunoterapia com o OncoTherad, a regressão tumoral e a sobrevida pós-tratamento em ratos induzidos quimicamente ao CBNMI. O OncoTherad foi eficaz na regressão tumoral e apresentou taxas de sobrevida maiores do que as estimadas para os doentes que sofrem dessa neoplasia. Diante dos resultados, podemos concluir que esta imunoterapia pode constituir uma promissora alternativa para o tratamento do CBNMI.

\section{Palavras-chave: Câncer de Bexiga, Imunoterapia, OncoTherad.}

\section{Introdução}

Globalmente, a cada ano, cerca de 400.000 novos pacientes são diagnosticados com Câncer de Bexiga (CB) e mais de 150.000 morrem da doença1. O tratamento primário do câncer de bexiga urinária nãomúsculo invasivo (CBNMI) baseia-se no tratamento cirúrgico através da ressecção transuretral, seguido da imunoterapia intravesical com $\mathrm{BCG}^{2,3}$. No entanto, os procedimentos cirúrgicos periódicos para a ressecção do tumor tornam o CB uma doença altamente mórbida e os efeitos colaterais estão presentes em mais de $90 \%$ dos pacientes tratados com BCG, desde sintomas irritativos leves até complicações graves que impossibilitam a continuação do tratamento. Considerando a importância do desenvolvimento de fármacos mais eficazes no tratamento do CBNMI, nosso grupo de pesquisa desenvolveu um composto sintético com propriedades antitumorais e imunológicas, denominado OncoTherad. Assim, os objetivos gerais deste estudo foram caracterizar 0 efeito antitumoral das estratégias terapêuticas utilizando o OncoTherad na sobrevida (SV) de ratos induzidos quimicamente ao CBNMI.

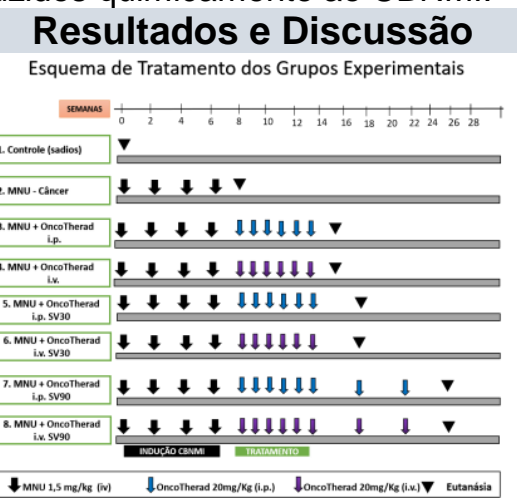

Figura 1. Esquema de tratamento dos grupos experimentais (ip: tratamento via intraperitoneal e iv: tratamento via intravesical).
Foram utilizadas ratas da variedade Fischer 344, na faixa etária de dez semanas, pesando em média 180 gramas. Os Grupos experimentais e o esquema de tratamento estão ilustrados na Figura 1. Após o procedimento experimental de cada grupo, os animais foram eutanaseados $e$ as bexigas urinárias coletadas e submetidas às análises histopatológicas

Nossos resultados demonstram que o tratamento com OncoTherad foi eficaz e não promoveu perda de peso corporal nos animais experimentais. O tratamento com OncoTherad na via intraperitoneal apresentou índices de regressão tumoral de 33,34\% (pós-tratamento), 42,84\% (SV30) e 71,43\% (SV90), e o tratamento na via intravesical resultou em índices de regressão tumoral de $66,67 \%$ (pós-tratamento), $57,14 \%$ (SV30) e 42,84\% (SV90). Além disso, nossos resultados demonstraram que as estratégias terapêuticas baseadas no uso do OncoTherad obtiveram taxa de sobrevida de $100 \%$, ou seja, não houve mortalidade nos animais experimentais.

\section{Conclusões}

O OncoTherad foi eficaz na regressão tumoral e apresentou taxas de sobrevida maiores do que as estimadas para os doentes que sofrem dessa neoplasia. Diante dos resultados, podemos concluir que esta imunoterapia pode constituir uma promissora alternativa para o tratamento do CBNMI.

\section{Agradecimentos}

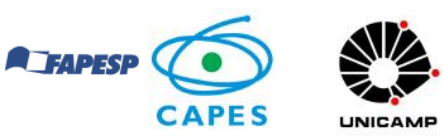

${ }^{1}$ American Cancer Society. Disponível http://www.cancer.org/cancer/bladdercancer/detailedguide/bladder-cancer-keystatistics. Acesso em: 21/05/2019.

${ }^{2}$ Askeland, E.J.; Newton, M.R.; O’donnell, M.A.; Luo, Y. Adv. Urol. 2012, 2012, 181987.

${ }^{3}$ Rafnar, T.; et al. Hum Mol Genet. 2011, 20, 4268-4281. 